\title{
O DIREITO À CONSULTA PRÉVIA DOS POVOS INDÍGENAS E CIDADANIA MULTICULTURAL NO BRASIL
}

\author{
${ }^{1}$ Germana Aguiar Ribeiro do Nascimento \\ ${ }^{2}$ Mércia Rejane Rangel Batista
}

\section{RESUMO}

Desde finais do século $\mathrm{XX}$, as reivindicações dos povos indígenas se tornaram frequentes, o que contribuiu para modificações nas legislações. Com efeito, direitos específicos aos indígenas são agora garantidos, é o caso do direito à consulta prévia. O objetivo deste artigo é examinar o acesso a este direito, observando-se em que medida está protegido e sua relação com a construção de uma cidadania multicultural. A investigação tem caráter qualitativo, partindo da análise da legislação e jurisprudência. Constata-se que, apesar da previsão legislativa, tal direito não é respeitado, o que impede a realização da cidadania multicultural no Brasil.

Palavras-chave: Povos indígenas, Cidadania multicultural, Direito à consulta prévia

\section{EL DERECHO A LA CONSULTA PREVIA DE LOS PUEBLOS INDÍGENAS Y CIUDADANÍA MULTICULTURAL EN BRASIL}

\section{RESUMEN}

Desde finales del siglo $\mathrm{XX}$, las reclamaciones de los pueblos indígenas se tornaran frequentes, lo que contribuyó para los cambios legislativos. En efecto, derechos indígenas son ahora garantizados, es el caso del derecho a consulta. El objetivo de este artículo es analizar el acceso de este derecho, observando en qué medida está protegido y su relación con la construcción de una ciudadanía multicultural. La investigación es de carácter cualitativo: son analizados la legislación y jurisprudencia. Se puede observar que a pesar de la legislación, él no es respectado, lo que impide la realización de una ciudadanía multicultural en Brasil.

Palabras-claves: Pueblos indígenas, Ciudadanía multicultural, Derecho a la consulta previa

\footnotetext{
1 Doutoranda em Direitos Humanos, Democracia e Justiça Internacional, pela Universidade de Valência. (Espanha). Email: germana_aguiar@hotmail.br

2 Doutora em Antropologia Social pela Universidade Federal do Rio de Janeiro - UFRJ, Rio de Janeiro. (Brasil). Professora da Universidade Federal de Campina Grande - UFCG, Paraíba. (Brasil). E-mail: mercia.batista1@ gmail.com
} 


\section{INTRODUÇÃO}

Historicamente, na construção daquilo que se pode designar enquanto Civilização Ocidental, depara-se com um esforço no qual se produziu sociedades nas quais a noção de coletividade se ancorou na certeza de uma universalidade que poderia ser atribuída aqueles tomados enquanto portadores dos elementos valorizados. Isto implicou em uma grande dificuldade para com todos aqueles que eram alocados como sendo membros externos ao mundo ocidental. Somente com discussões, lutas e confrontos é que se foi a partir do século $\mathrm{XX}$ incorporando a ideia do direito e da diversidade, contemplando o espaço no qual o campo da filosofia do direito se abriu para uma discussão sobre diversidade.

O artigo $4^{\circ}$ da Declaração Universal da UNESCO sobre a diversidade cultural destaca que a defesa da diversidade cultural é um imperativo ético, inseparável do respeito da dignidade da pessoa humana. Com efeito, vários grupos, a exemplo dos povos indígenas, são e foram submetidos, por séculos, às piores formas de tratamento, tendo suas liberdades fundamentais violadas. Ora, esses grupos enriquecem a diversidade cultural e merecem ser não somente protegidos, como reconhecidos, para que seus modos de vida, suas crenças, práticas religiosas e modos culturais possam se perpetuar. Ao final do século XX, vários povos começam assim a manifestar suas reivindicações e aspirações, dentre estes, os povos indígenas (YACOUB, 2009).

Na América Latina, o final do século XX é marcado pelo surgimento de movimentos sociais de luta pelos direitos dos povos indígenas. Com efeito, os índios passam a constituir esses movimentos e a construir suas pautas, enunciando suas reivindicações. Esses movimentos suscitaram, no Brasil, vários encontros com o objetivo de discutir a situação desses povos e seus direitos. No cenário internacional, tivemos a publicação, a partir dos anos 70, dos estudos sobre discriminação das Nações Unidas. Assim, Santa Cruz (1971) e Martinez Cobo (1986) contribuem para discussão acerca da questão dos povos indígenas.

Segundo a Organização das Nações Unidas (2010), os povos indígenas contam com cerca de 370 milhões de membros. Na América Latina, a população indígena é entre 30 e 40 milhões de pessoas, contando, o Brasil, em 2010, com 817.000 indígenas, segundo o Instituto Brasileiro de Geografia e Estatística (IBGE). Desde a invasão dos colonizadores, esse grupo vê suas terras sendo invadidas e seus sistemas político, econômico e social desprezados (NASCIMENTO, 2013).

Uma das definições oficiais de povos indígenas é a elaborada pela Organização Internacional do Trabalho (OIT), na Convenção n. 169. São, assim, os povos indígenas "povos em países independentes, considerados indígenas pelo fato de descenderem de 
populações que habitavam o país ou uma região geográfica pertencente ao país na época da conquista ou da colonização ou do estabelecimento das atuais fronteiras estatais e que, seja qual for sua situação jurídica, conservam todas as suas próprias instituições sociais, econômicas, culturais e políticas, ou parte delas". Esta Convenção representa um dos tratados mais avançados em matéria de proteção dos direitos dos povos indígenas. Além disso, leva em consideração o caráter histórico, a especificidade cultural, a autodeterminação e a situação não dominante dos indígenas.

A partir da metade do século XX, nota-se, assim, que um sistema normativo de proteção aos direitos indígenas vai sendo instaurado. O direito à consulta prévia é um dos direitos garantidos nesse sistema. Ele afirma que as comunidades indígenas devem ser consultadas cada vez que medidas legislativas ou administrativas previstas sejam suscetíveis de afetá-las. Nesse contexto, este artigo se propõe a examinar em que medida o direito à consulta dos povos indígenas é reconhecido e garantido no plano internacional e nacional e sua relação com à implementação de uma cidadania multicultural no Brasil. Com efeito, para se considerar um Estado multicultural, as distintas comunidades do país devem ser igualmente valiosas e gozar do grau necessário de autonomia política para desenvolver suas próprias instituições (TORBISCO, 2013). O direito à consulta dos povos indígenas é, assim, elemento essencial para a implementação desse Estado. Trata-se, desse modo, de um estudo exploratório de caráter qualitativo e cunho bibliográfico e documental, que parte da análise de documentos atinentes à legislação nacional e internacional e decisões jurisprudenciais.

\section{O DIREITO À CONSULTA PRÉVIA DOS POVOS INDÍGENAS NA LEGISLAÇÃO NACIONAL E INTERNACIONAL}

A Constituição Brasileira de 1988 é bastante inovadora no que concerne aos direitos dos povos indígenas. Trata-se do primeiro texto constitucional que protege os povos indígenas sem o intuito de integrá-los à sociedade brasileira. Ademais, assegura que os direitos humanos previstos nos tratados de direito internacional dos quais o Brasil é parte, são integrados no bloco constitucional.

Na verdade, a Constituição Federal de 1988 rompe um período extenso de tratamento legal inadequado, marcado por um ordenamento jurídico pautado na abordagem eurocêntrica da temática dos povos indígenas. Nesse sentido, inovou, ao preconizar uma interação horizontal entre os povos indígenas e o Estado Brasileiro, marcada "pelo respeito à diversidade, por meio do reconhecimento da pluralidade de culturas" (BELFORT, 2006, p. 25).

Para Silva (2007), a Constituição da República Federativa do Brasil revela a 
preocupação do Constituinte em preordenar um sistema de normas que pudesse efetivamente tutelar os direitos e interesses dos povos indígenas. Nesse sentido, ao consagrar os princípios do multiculturalismo e do pluralismo jurídico, a Carta Magna identifica os indígenas como cidadãos brasileiros, atribuindo a eles direitos e garantias, em consonância com o princípio da igualdade.

E seguindo essa lógica que o direito à consulta foi consagrado no art. $231, \S 3^{\circ}$ da Constituição Federal de 1988, garantindo constitucionalmente a consulta prévia, livre e informada das comunidades afetadas no caso do aproveitamento de recursos:

Art. 231. São reconhecidos aos índios sua organização social, costumes, línguas, crenças e tradições, e os direitos originários sobre as terras que tradicionalmente ocupam, competindo à União demarcá-las, proteger e fazer respeitar todos os seus bens.

$\S 3^{\circ} \mathrm{O}$ aproveitamento dos recursos hídricos, incluídos os potenciais energéticos, a pesquisa e a lavra das riquezas minerais em terras indígenas só podem ser efetivados com autorização do Congresso Nacional, ouvidas as comunidades afetadas, ficandolhes assegurada participação nos resultados da lavra, na forma da lei.

Além da Carta Magna, em dezembro de 2008, o Supremo Tribunal Federal atribuiu status constitucional para os tratados de direitos humanos, mediante decisão dos RE 466.346SP e HC 87.585- TO. Nesse sentido, sendo o Brasil signatário da Convenção n. 169 da OIT, sustenta-se que o artigo, 231, $\S 3^{\circ}$ da Constituição Federal de 1988 deve ser interpretado de forma combinada com a referida Convenção.

O direito à consulta está, assim, tutelado a nível internacional através da Convenção n. 169 da Organização Internacional do Trabalho - OIT, acerca dos povos indígenas, ratificada pelo Brasil em 19/06/2002, por meio do Decreto Legislativo n. 143/2002 e promulgada por meio do Decreto 5.051, de 19 de abril de 2004:

Ratificação da Convenção 169 da OIT - O Brasil ratificou a Convenção no 169 da OIT, em Genebra, em 25 de julho de 2002, mediante o Decreto Legislativo n.143, de 20- 6- 2002. Entrou em vigência em julho de 2003. Hierarquia das Convenções da OIT no direito interno a Convenção 169 é equiparada à lei ordinária com hierarquia intermediária entre a Constituição Federal e as leis ordinárias comuns no sistema jurídico brasileiro (Consulta Livre, Prévia e Informada na Convenção n 169 da OIT).

A referida Convenção estabelece a consulta prévia, livre e informada ao índio, no seu artigo $6^{\circ}$ que dispõe:

1. Ao aplicar as disposições da presente Convenção, os governos deverão:

a) consultar os povos interessados, mediante procedimentos apropriados e, particularmente, através de suas instituições representativas, cada vez que sejam previstas medidas legislativas ou administrativas suscetíveis de afetá-los diretamente;

b) estabelecer os meios através dos quais os povos interessados possam participar 
livremente, pelo menos na mesma medida que outros setores da população e em todos os níveis, na adoção de decisões em instituições efetivas ou organismos administrativos e de outra natureza responsáveis pelas políticas e programas que lhes sejam concernentes;

c) estabelecer os meios para o pleno desenvolvimento das instituições e iniciativas dos povos e, nos casos apropriados, fornecer os recursos necessários para esse fim.

2. As consultas realizadas na aplicação desta Convenção deverão ser efetuadas com boa fé e de maneira apropriada às circunstâncias, com o objetivo de se chegar a um acordo e conseguir o consentimento acerca das medidas propostas.

Além disso, no artigo $7^{\circ}$, da Convenção, observa-se o direito dos indígenas de eleger suas próprias prioridades, o que é afirmado com o objetivo de garantir a autonomia dos povos indígenas (BELLIER, 2010):

1. Os povos interessados deverão ter o direito de escolher suas próprias prioridades no que diz respeito ao processo de desenvolvimento, na medida em que ele afete as suas vidas, crenças, instituições e bem-estar espiritual, bem como as terras que ocupam ou utilizam de alguma forma, e de controlar, na medida do possível, o seu próprio desenvolvimento econômico, social e cultural. Além disso, esses povos deverão participar da formulação, aplicação e avaliação dos planos e programas de desenvolvimento nacional e regional suscetíveis de afetá-los diretamente.

A Assembleia Geral das Nações Unidas adotou a Declaração sobre os direitos dos povos indígenas no dia 13 de Setembro de 2007, sendo o Brasil um dos países que a ratificaram. Trata-se de um texto que vem reafirmar os direitos já garantidos pela Convenção n. 169, reforçando os direitos desses grupos. O direito à consulta é protegido por vários artigos desse texto, é o caso, a título de exemplo, dos artigos 10, 11, 15, 17 e 19. Destaca-se, o artigo 10 que preceitua:

Os povos indígenas não serão removidos à força de suas terras ou territórios. Nenhum traslado se realizará sem o consentimento livre, prévio e informado dos povos indígenas interessados e sem um acordo prévio sobre uma indenização justa e eqüitativa e, sempre que possível, com a opção do regresso.

Nesse sentido, Verdum (2011) afirma que o direito a consulta prévia inclui todas aquelas decisões administrativas e legislativas, de nível federal, estadual e municipal, que afetem direitos coletivos dos povos indígenas. Além disso, acrescenta que o Poder Executivo deve consultá-los sobre as iniciativas legislativas que pretende desenvolver, incluídas as medidas provisórias (MPs) que afetem direitos coletivos desses povos. Como se observa, a proteção de outros direitos indígenas, como o direito à terra, por exemplo, pode ser garantida através da consulta, mecanismo previsto tanto na legislação internacional quanto no contexto da própria Constituição Federal, o que corrobora sua importância. Possibilita-se, portanto, o diálogo direto com as comunidades afetadas.

Apesar do caráter essencial deste direito, ele ainda não foi devidamente regulamentado no Brasil, o que é extremamente grave para os povos indígenas. Com efeito, o 
modelo de desenvolvimento econômico adotado tem gerado constantes conflitos em torno das terras indígenas e dos recursos nelas encontrados. Esta situação é claramente demonstrada quando se debruça sobre o processo de construção da Usina Hidrelétrica de Belo Monte e como os mecanismos legais foram insuficientes para garantir os direitos indígenas, como se pode depreender do dossiê organizado por João Pacheco de Oliveira e Clarice Cohn em 2014 e publicado pela associação brasileira de antropologia.

Em Informe de 2015 (DUE PROCESS OF LAW FOUNDATION, 2015, p. 23), a Fundação do Devido Processo Legal alerta que o Brasil é o país que apresenta o menor avanço em termos de regulamentação da consulta prévia, o que proporciona a subsistência dos conflitos sociais vinculados à extração de recursos naturais. A Fundação (2015, p. iv) explicita ainda que tal fato ocorre devido à persistência de causas estruturais que estão nas raízes das violações dos direitos indígenas, tais como, a discriminação, que permeia o aparato estatal ao longo de séculos de história. Além disso, a Fundação (2015, p. iv) destaca que:

a falta de consulta para a imposição de uma hidroelétrica apesar das vidas humanas em risco, a destruição de comunidades para a implementação de projetos econômicos, a venda a terceiros de terras historicamente ocupadas por povos indígenas e tribais, são expressões desta discriminação, traduzidas pelo desinteresse por demandas de desenvolvimento baseadas em uma relação harmônica entre os povos indígenas e os recursos naturais que se encontram em seus territorios.

A falta de regulamentação é, assim, um dos fatores que demonstram a resistência do Estado brasileiro de tornar efetivo o direito à terra. Entretanto, a Comissão Interamericana de Direitos Humanos (CIDH, 2009) enfatiza que a ausência de regulamentação não exime o Estado do dever de respeitar o direito à consulta.

O Brasil ratificou a Convenção Interamericana de Direitos Humanos em 9 de Julho de 1992, sendo, pois, obrigado a respeitar os direitos assegurados por esse texto. Os orgãos do Sistema Interamericano de Proteção dos Direitos Humanos, do qual o Brasil é parte, vêm constituindo atores fundamentais, estabelecendo decisões cada vez mais favoráveis às comunidades indígenas, obrigando os Estados a respeitar os textos adotados (RINALDI, 2009). O direito à consulta se encontra, assim, também, tutelado pelo aparato jurídico deste sistema. O parágrafo 273 da sistematização das normas e jurisprudência do Sistema Interamericano de Direitos Humanos (CIDH, 2009) dispõe que:

Os Estados tem a obrigação de consultar os povos indígenas e garantir sua participação nas decisoes relativas a qualquer medida que afete seus territorios, tomando em consideração a especial relação entre os povos indígenas e tribais e a terra e seus recursos naturais. Esta é uma manifestação concreta da regra geral segundo a qual o Estado deve garantir que "os povos indígenas sejam consultados sobre os temas suscetíveis de afeta-los", levando em conta que esta consulta deve 


\begin{abstract}
"estar dirigida a obter seu consentimento livre e informado", segundo dispoe a Convenção 169 da OIT e a Declaração dos direitos dos povos indígenas. A consulta e o consentimento não se limitam a assuntos que afetem os direitos de propriedade indígenas, mas também sao aplicaveis a outras acoes administrativas ou legislativas dos Estados que tenham impacto sobre os direitos ou interesses dos povos indígenas.
\end{abstract}

De acordo com a Comissão Interamericana de Direitos Humanos (2009), o direito à consulta prévia e o dever correlativo do Estado estão diretamente vinculados a múltiplos direitos humanos, e em particular, ao artigo 23 da Convenção Interamericana. Este artigo reconhece o direito de todos os cidadãos de "a. participar na direção dos assuntos públicos, diretamente ou por meio de representantes livremente eleitos". No contexto dos povos indígenas, a Comissão destaca que a participação política inclui o direito dos povos indígenas de participar na tomada de decisões sobre políticas e assuntos que incidam ou possam incidir em seus direitos, de acordo com seus valores, usos, costumes e formas de organização.

A Corte Interamericana de Direitos Humanos destaca em um Informe de 2000 (CIDH, 2000) que o cumprimento do dever estatal de consulta deve regular-se no ordenamento juridico interno através de medidas legislativas ou administrativas, de tal maneira que se garanta plenamente o príncipio de legalidade e a certeza juridica a todos os atores implicados. Afirma ainda que os Estados devem aprovar legislação que desenvolva os direitos individuais dos indígenas, que garanta os mecanismos de participação dos povos indígenas na tomada de decisões de índole política, econômica e social que afetem seus direitos e que incremente sua participação política na adoção de decisões a nivel nacional.

Nesse contexto, observa-se que o direito internacional e nacional asseguram a proteção do direito à consulta dos povos indígenas. Todavia, nota-se que, há grande resistência para realização deste direito.

\title{
3 O DESRESPEITO DO DIREITO À CONSULTA COMO LIMITE À REALIZAÇÃO DA CIDADANIA MULTICULTURAL
}

A não-efetividade do direito à consulta prévia dos povos indígenas no Brasil fere diretamente o modelo de Estado multicultural que o país adota, segundo o qual se reconhece no seio de sua Constituição a diversidade cultural da sociedade brasileira e sua relevância intrínseca. Um Estado multicultural supõe que suas distintas comunidades culturais gozem de autonomia política para desenvolver suas prioridades. A Constituição Federal reconhece, desse modo, direitos específicos aos povos indígenas, dentre eles, o direito à consulta prévia, para que estes grupos tenham autonomia. Apesar de estar garantido pela legislação nacional e internacional, este direito é constantemente desrespeitado. Com efeito, em um Informe de aplicação das normas internacionais do trabalho de 2011 (OIT, 2011), a Comissão de 
especialistas em aplicação de Convenções e Recomendações, instituída pelo Conselho de Administração da Organização Internacional do trabalho enfatiza que

a consulta e participação não devem ser somente formais, pois assim se esvaziaria seu conteúdo, mas deve constituir um verdadeiro diálogo, mediante mecanismos adequados, para que resulte em projetos inclusivos, nos quais os povos cobertos pela Convenção possam ser participantes ativos do seu desenvolvimento. A Convenção convida o governo a examinar os mecanismos de consulta e participação existentes, em cooperação com as organizacoes indígenas, de modo a assegurar-se que guardam conformidade com a Convenção.

O Informe (OIT, 2011) acrescenta que os governos tem a obrigação de consultar os povos protegidos pela Convenção cada vez que prevejam medidas legislativas ou administrativas suscetíveis de afetá-los e aponta cinco casos nos quais o governo brasileiro não respeitou o direito à consulta prévia dos povos indígenas, quais sejam:

1) Hidrelétrica de Belo Monte; 2) transposição do Rio São Francisco; 3) Projeto de Lei número 2540/2006 que propõe autorização para uma hidrelétrica na Cachoeira de Tamanduá, no rio Cotingo, na Terra Indígena Raposa Serra do Sol; 4) situação da terra indígena dos Guarani-Kaiwoa, onde vivem 12.000 indígenas Guarani-Kaiwoá como os da terra Indígena de Dourados, que vivem em miséria total e onde se implementam projetos e políticas publicas sem nenhuma consulta ou participação; e 5) mineração na Terra Indígena dos Cinta-Largas, onde terá forte impacto a lei sobre mineração em trâmite no Congresso Nacional, sem consulta desse povo.

Em relação ao terceiro caso citado, destaca-se que em 2008, o Comitê para eliminação da discriminação racial já havia enviado carta ao governo brasileiro (CERD, 2008), pedindo ao Estado informações detalhadas sobre a situação da terra dos povos indígenas "Raposa Serra do Sol". Nela, o Comitê ressalatava a necessidade de que medidas fossem tomadas para que todos os ocupantes ilegais das terras desse grupo fossem retirados pacificamente e que os indígenas fossem informados e que sua autorização fosse requerida para a exploração dos recursos hídricos presentes.

Em razão do Informe da OIT de 2011, o governo brasileiro instaurou, em janeiro de 2012, através da Portaria n 35, um Grupo de Trabalho Interministerial, com os objetivos descritos no seu art. $2^{\circ}$ que segue:

Art. $2^{\circ} \mathrm{O}$ Grupo de Trabalho Interministerial dialogará de forma permanente com representantes dos povos indígenas, comunidades tradicionais e com a sociedade civil organizada, nos termos da Convenção no 169 da OIT.

$\S 1^{\circ}$ São objetivos desse diálogo: I - planejar a realização de reuniões informativas e consultivas com os sujeitos de direitos da Convenção n ${ }^{\circ} 169$ da OIT;

II - contribuir no processo de sistematização dos resultados das reuniões informativas e consultivas visando à construção de minuta de instrumento de regulamentação dos mecanismos de consulta prévia previstos na Convenção no 169 da OIT;

III - contribuir na elaboração de proposta do instrumento de regulamentação dos 
mecanismos de consulta prévia previstos na Convenção nº 169 da Organização Internacional do Trabalho;

IV - monitorar e avaliar o processo de regulamentação.

$\mathrm{Na}$ verdade, apesar do intuito do Grupo de trabalho ser o de regulamentar o procedimento de consulta prévia, poucas comunidades indígenas foram convidadas a participar das discussões, o que é completamente contraditório. Isto demonstra que o Brasil ainda não é uma sociedade que respeita as diferenças, o que coloca em xeque a cidadania multicultural no país. Com efeito, como afirma Verdum (2008):

\begin{abstract}
se aceitamos a premissa de que uma cidadania multicultural implica o reconhecimento juridico de direitos politicos e sociais aos povos indígenas - e com isso o direito à autonomia na tomada de decisões, o autogoverno de seus territórios e dos recursos neles existentes, a representação política nas instâncias do poder legislativo e o papel protagonista na formulação e no controle das políticas públicas que tem a ver com seus interesses e necessidades, no Brasil ainda nos econtramos muito distantes do ideal de democracia e cidadania que tal noção carrega.
\end{abstract}

As Associações indígenas demonstram, assim, suas preocupações com a pequena participação de povos indígenas e comunidades interessadas nas reuniões relativas ao processo de regulamentação da consulta prévia. Conectas Direitos Humanos e Justiça Global (CONECTAS, 2013) alertaram, consequentemente, que as audiências públicas para regulamentação não estavam abrangendo o universo dos povos indígenas e que estavam distorcendo os princípios dos textos internacionais.

A não-participação das comunidades indígenas nessas discussões se coaduna com outras políticas do governo, tais como a prevista na Portaria 303 da Advocacia Geral da União, que atenta contra a Convenção n. 169. A Portaria 303 da Advocacia Geral da União se refere à decisão do Supremo Tribunal Federal de abril de 2009, na qual a Corte decide o caso do território Raposa Terra do Sol no Estado de Roraima. A decisão é favorável aos povos indígenas do território Raposa Terra do Sol, entretanto, os ministros estabelecem condiçoes para que o usufruto indígena seja autorizado, violando completamente o direito à consulta prévia, protegido pela Carta Magna e pelos textos internacionais:

(v) o usufruto dos índios não se sobrepõe ao interesse da política de defesa nacional; a instalação de bases, unidades e postos militares e demais intervenções militares, a expansão estratégica da malha viária, a exploração de alternativas energéticas de cunho estratégico e o resguardo das riquezas de cunho estratégico, a critério dos órgãos competentes (Ministério da Defesa e Conselho de Defesa Nacional), serão implementados independentemente de consulta às comunidades indígenas envolvidas ou à FUNAI; (vi) a atuação das Forças Armadas e da Polícia Federal na área indígena, no âmbito de suas atribuições, fica assegurada e se dará independentemente de consulta às comunidades indígenas envolvidas ou à FUNAI; 
Nota-se o total desrespeito para com os povos indígenas e a violação de direitos já protegidos. Em decorrência disso, em carta pública, a Articulação dos povos indígenas do Brasil (2013) manifestou sua insatisfação, haja vista que o governo brasileiro pretendia regulamentar o procedimento, mas, sempre afrontando o direito à consulta prévia, não somente através do trabalho do Grupo, como também de outras decisões:

\begin{abstract}
O governo tem insistido em prosseguir com a regulamentação, apesar das sucessivas afrontas por ele praticadas contra o próprio direito de consulta e consentimento livre, prévio e informado, por meio de instrumentos jurídicos e administrativos que negam de forma absurda e rotundamente esse direito, como o faz a maléfica Portaria 303 (...) Reafirmamos nosso posicionamento de não discutir a regulamentação da Convenção 169 da OIT enquanto o governo federal não revogar definitivamente a Portaria 303 da AGU - que atenta contra a referida convenção - e conclamamos as organizações não-governamentais, movimentos sociais e toda a sociedade civil que nos apóiem nessa decisão.
\end{abstract}

Valiente (2013, p. 68) afirma que para a implementação de um Estado multicultural, não somente deve significar um reconhecimento a nivel constitucional, como também deve ser parte das politicas publicas e um elemento integral na formação da sociedade atual. Acrescenta que leis devem ser criadas para tornar esse Estado moderno multicultural realidade, o que implicaria não somente que os povos indígenas exercessem seus direitos, como também que o resto da sociedade respeitasse e valorizasse a cultura indígena.

Ora, no Brasil, o direito à consulta vem sendo constantemente violado, o que corrobora que os indígenas não exercem seus direitos, estando, o Brasil, portanto, longe de ser um Estado que respeita sua diversidade cultural. Para piorar ainda a situação, a Portaria 303 da Advocacia Geral da União de 16 de Julho de 2012 observa que as condições determinadas pelo Supremo Tribunal Federal para o território Raposa Terra do Sol são aplicáveis a todos os povos indígenas do Brasil. Ante a pressão das organizações em prol dos direitos indígenas, em fevereiro de 2014, o Supremo Tribunal Federal determinou que tal decisão se aplicava somente aos povos indígenas do território em questão. Apesar disso, a Advocacia Geral da União publica outra portaria, no mesmo mês, a Portaria 27/2014, que mantém em vigor a Portaria 303. Em virtude deste documento, as associações indígenas passaram a boicotar qualquer relação com o Grupo de trabalho que pretendia regulamentar o direito à consulta prévia, já que o governo havia estabelecido tantas medidas contrárias a tal direito.

Para Valiente (2013, p. 68) "o futuro do Estado e dos Estados é o reconhecimento real e efetivo de que sua sociedade está cimentada em diferentes culturas, e assim, é multicultural. Este reconhecimento é a base da convivência pacífica entre diferentes culturas que existem nele". O constante desrespeito ao direito à consulta prévia demonstra que no Brasil esse reconhecimento real e efetivo ainda não saiu do papel. 
Corrobora este fato, a tendência do Supremo Tribunal Federal e do Superior Tribunal de Justiça de rechaçar qualquer decisão de primeira e segunda instância que venha a determinar a suspensão de megaprojetos que não respeitaram o direito à consulta prévia. A título de exemplo, o caso da construção da Usina Hidroelétrica de Belo Monte, que foi suspensa pelo Tribunal Regional Federal da primeira região por ausência de consulta prévia dos povos indígenas, mas em seguida, reautorizada pela Corte suprema.

A Corte Interamericana de Direitos Humanos afirma, em um informe de 2004, que um dos elementos centrais para a proteção dos direitos de propriedade dos indígenas é o requisito de que os Estados estabeleçam consultas efetivas e previamente informadas com as comunidades indígenas em relação aos atos e decisões que possam afetar seus territórios tradicionais. Trata-se, assim, de um direito essencial à proteçao dos territórios indígenas, garantido pela legislação nacional e pelo Sistema Internacional de Proteção dos Direitos Humanos.

Apesar disso, nenhum dos sucessivos governos aceitou realizar as modificações necessárias na estrutura e nas práticas político-gerenciais do aparato do Estado nacional para garantir o caráter multicultural da sociedade brasileira reconhecido pela lei (VERDUM, 2008). Em verdade, o que procuramos demonstrar é uma situação social e política na qual o reconhecimento de direitos e da existência de povos e grupos minoritários, tem sido combatido. Sob diferentes argumentos, sendo que na sua maior parte há a construção de falácias e que permitem indicar uma valorização do discurso construído no período do regime militar.

Outra situação que confirma a inobservância do caráter multicultural da sociedade brasileira é a Proposta de Emenda Constitucional n. 215/2000. Com efeito, a proposta apresentada pelo deputado federal Almir Sá e outros visa acrescer o inciso XVIII ao artigo 49, modificar o $\$ 4^{\circ}$ e acrescentar o $\S 8^{\circ}$ ambos no artigo 231, da Constituição da República Federativa do Brasil. Nesse sentido, tem por objetivo incluir dentre as competências exclusivas do Congresso Nacional, a aprovação de demarcação das terras tradicionalmente ocupadas pelos índios e a ratificação das demarcações já homologadas, estabelecendo que os critérios e procedimentos de demarcação serão regulamentados por lei.

Portanto, a PEC 215 é uma Proposta de Emenda Constitucional que tem por intento dar o poder aos parlamentares de criar e também anular demarcações de terras indígenas, quilombolas e unidades de conservação, incumbência, hodiernamente, do Poder Executivo de demarcar Áreas Protegidas. Transfere-se, assim, a palavra final acerca de demarcação das terras das comunidades e das unidades de conservação do Executivo para a Câmara dos Deputados. Constata-se, no tocante à PEC 215, a ausência de consulta da população indígena. 
Ela tramita na Câmara há 15 anos sem nunca ter levado em conta a opinião dos povos tradicionais, violando, portanto, o direito à consulta.

Verdum (2008) alerta que o que ocorre no Brasil é uma continuação do projeto integracionista, através do qual, acredita-se que as comunidades indígenas devem ser integradas na sociedade, não tendo direito, portanto, à autonomia. Este autor adiciona ainda que a politica governamental brasileira prefere adotar uma posição de assistencialismo em detrimento de considerar os povos indígenas como sujeitos de direitos com autonomia para definir suas prioridades futuras. $\mathrm{O}$ desrespeito à consulta prévia se demonstra, assim, como uma limitação bastante grande do caráter multicultural da sociedade brasileira. Como também uma marcada dificuldade por parte do Estado e da sociedade civil em compreender os efeitos dos movimentos políticos instaurados pelo movimento indígena (LIMA, 2015).

Para que haja uma verdadeira cidadania multicultural, é preciso evitar injustiças decorrentes da desconsideração das necessidades particulares de alguns grupos da população, é preciso deter a exclusão desses grupos, as políticas públicas devem ter em conta as necessidades reais e específicas dos distintos grupos sociais e culturais para que haja uma equidade real entre os indivíduos (GARCIA GIRALDEZ, 2000). No Brasil, há o reconhecimento das necessidades específicas das comunidades indígenas, entretanto, na prática, tais peculiaridades não são respeitadas.

A cidadania multicultural é, assim, longe de ser realidade no Brasil. As comunidades indígenas têm, há mais de 500 anos, seus direitos fundamentais serem violados constantemente, apesar de todo aparato legal que os protege. Nesse sentido, em 2009, o Relator especial sobre a situação dos direitos humanos e liberdades fundamentais dos povos indígenas da ONU, James Anaya, publicou um relatório sobre a situação dos povos indígenas no Brasil (HRC, 2009). Nele, o Relator constata que o governo brasileiro se engaja na proteção dos direitos desses grupos em termos de legislação. Apesar disso, ele observa que os direitos dos povos indígenas continuam a ser desrespeitados.

Em um relatório de 2012 (HRC, 2012), o Relator invoca as recomendações dadas ao Brasil em uma Conferência organizada pelo governo brasileiro e afirma a necessidade de que mais medidas sejam tomadas a fim de que os povos indígenas possam definir suas próprias prioridades de desenvolvimento, evocando os procedimentos de consulta prévia obrigatórios no que concerne às decisões legislativas e administrativas afetando esses grupos, sobretudo no que se refere às atividades industriais. Segundo o relator, as prioridades de desenvolvimento dos povos indígenas devem estar em primeiro plano. Enquanto essa participação dos indígenas não for possivel, não se poderá falar em cidadania multicultural no país. 
Do mesmo modo, a Comissão Interamericana de direitos humanos constata a violação dos direitos do povo indígena Yanomami (CIDH, 1985), situados no norte do Brasil. Ela recomenda ao governo brasileiro a adoção de medidas sanitárias para proteger a vida e a saúde dos indígenas, assim como a delimitação das terras do Parque Yanomami. A Comissão ressalta ainda que os Yanomami deveriam ser previamente consultados no que concerne à instalação de programas de educação e de proteção médica.

O artigo 7, parágrafo primeiro da Convenção n. 169 prevê que:

\begin{abstract}
Os povos interessados deverão ter o direito de escolher suas, próprias prioridades no que diz respeito ao processo de desenvolvimento, na medida em que ele afete as suas vidas, crenças, instituições e bem-estar espiritual, bem como as terras que ocupam ou utilizam de alguma forma, e de controlar, na medida do possível, o seu próprio desenvolvimento econômico, social e cultural. Além disso, esses povos deverão participar da formulação, aplicação e avaliação dos planos e programas de desenvolvimento nacional e regional suscetíveis de afetá-Ios diretamente.
\end{abstract}

Desse modo, há uma complementaridade entre o direito à terra, direito à consulta prévia, os direitos culturais e a autonomia dos povos indígenas. Tratam-se de direitos que são interdependentes. Será somente com o devido respeito desses direitos que a identidade cultural dos povos indígenas poderá se perpetuar e, assim, que a cidadania multicultural poderá ser concretizada no país. A Comissão Interamericana de direitos humanos (2009) destaca que

\begin{abstract}
o direito dos povos indígenas a serem consultados sobre as decisões que possam afetá-los se relaciona diretamente com o direito à identidade cultural, na medida em que a cultura pode resultar afetada por tais decisões. O Estado deve respeitar, proteger e promover as tradições e costumes dos povos indígenas e tribais, por serem estas um componente intrínseco da identidade cultural das pessoas que conformam tais povos. A obrigação estatal de desenvolver processos de consulta com respeito as decisões que afetem o território se vincula diretamente, assim, à obrigação estatal de adotar medidas especiais para proteger o direito à identidade cultural, baseado em uma forma de vida intrinsecamente ligada ao território.
\end{abstract}

Assim, sustenta-se que os direitos especificos aos povos indigenas são reconhecidos e outorgados pelo Estado brasileiro em virtude do pertencimento desses grupos à uma cultura diferente da majoritária. Todavia, será somente com o respeito desses direitos específicos que haverá um justo equilíbrio entre os grupos indigenas e os grupos majoritários e, destarte, uma cidadania multicultural, onde todos tenham o direito de participar igualmente, de acordo com suas diferenças. O ideal de cidadania multicultural, sem o respeito dos direitos dos povos indigenas, está, assim, longe de ser alcançado no Brasil. O assassinato do menino indígena da tribo dos Kaingang, no final de 2015, em uma rodoviária brasileira, é apenas um reflexo da mentalidade que permeia este pais (TORRES, 2016). Ela discrimina, exclui os povos indígenas e viola abertamente os seus direitos, sob o manto do Estado. A violação do direito à consulta prévia e informada é apenas mais uma num país onde o colonialismo e a política in- 
tegracionista parecem persistir desde o século XVI. Como afirma Verdum (2008), concepções que pareciam enterradas em um passado distante ainda seguem ativas e orientam o discurso e a prática da administração indigenista oficial.

\section{CONSIDERAÇÕES FINAIS}

Da época colonial aos dias atuais, os povos indígenas lutam por uma vida digna no Brasil e no mundo. Esses grupos nunca viram seus valores e culturas respeitados de forma efetiva. A história deles mostra que para sobreviver enquanto povo indígena é preciso resistir à força de vários atores: os grandes proprietários de terra, os grandes empresários, a população civil e o Estado.

A resistência e as reivindicações dos povos indígenas nas últimas décadas obrigaram os Estados a modificarem suas visões. Houve, assim, a elaboração de leis protegendo seus direitos. A Constituição Brasileira de 1988 anuncia o respeito aos direitos e liberdades fundamentais dos povos indígenas, o princípio de igualdade e de não-discriminação, o direito à terra e o direito à consulta prévia. Nesse mesmo sentido, a comunidade internacional elaborou textos e mecanismos para proteger os povos indígenas.

Apesar disso, é possível verificar que eles ainda não se beneficiam do gozo de todos esses direitos, mesmo com tantos textos internacionais, dos quais o Brasil é signatário, e nacionais com vistas a protegê-los. O direito à consulta é um desses direitos ameaçados constantemente.

É latente no contexto brasileiro o aumento da pressão sobre as terras indígenas em virtude dos recursos naturais e da expansão da fronteira agrícola. Neste cenário, observa-se que tentam impor os interesses econômicos em detrimento dos direitos das comunidades tradicionais, relativos, inclusive, ao próprio direito de existir no futuro, de acordo com seus valores e modos de vida.

É, assim, primordial que os órgãos internacionais continuem com sua ação de proteção para que os Estados modifiquem sua política relacionada aos povos indígenas. È fundamental que o Estado brasileiro torne efetivo o direito dos povos indígenas à diferença, ao direito originário a suas terras e territórios e o direito à consulta prévia, somente assim haverá uma cidadania multicultural no país. 


\section{REFERÊNCIAS}

ARTICULAÇÃO DOS POVOS INDÍGENAS DO BRASIL. (2013, 26 de julho). Carta Pública da APIB sobre a regulamentação dos procedimentos do direito de consulta assegurado pela convenção 169 da OIT. Combate Racismo Ambiental. Disponível em http://www.cimi.org.br/site/pt-br/?system=news\&action=read\&id=7045. Acesso em: 30 Dez. 2015.

BELFORT, L. F. I. A proteção dos conhecimentos tradicionais dos povos indígenas, em face da convenção sobre diversidade biológica. Brasília: Faculdade de Direito. Universidade de Brasília, 2006.

BELLIER, I. Les Peuples Autochtones et la crise mondiale. Multitudes. n. 41, 2010.

BRASIL. Supremo Tribunal Federal (STF). Petição 3.388 Roraima. Relator: CARLOS BRITTO, Data de Julgamento: 03/04/2009, Data de Publicação: DJe-071 DIVULG 16/04/2009 PUBLIC 17/04/2009). Petição 3.388-4 Roraima.

CERD. Letter from UN Committee on the Elimination of Racial Discrimination (CERD) to the Government of Brazil. Disponível em: http://www.forestpeoples.org/region/brazil/publication/2010/raposa-serra-do-sol-letter-uncommittee-elimination-racial-discrimina. Acesso em: 30 Dez. 2015.

CIDH. Derechos de los pueblos indígenas y tribales sobre sus tierras ancestrales y recursos naturales. Normas y jurisprudencia del Sistema Interamericano de Derechos Humanos. OEA/Ser.L/V/II, Doc.56/09, 30 de diciembre de 2009.

CIDH. RESOLUCION N $N^{o}$ 12/85 CASO 7615 PUEBLO YANOMAMI. Disponível em : http://www.cidh.oas.org/indígenas/JURISPRUDENCIA/CASOS. Acesso em: 15 Nov 2014.

CIDH. Informe No. 40/04. Caso 12.053, Comunidades Indígenas Mayas del Distrito de Toledo (Belice), 12 de octubre de 2004.

CIDH. Segundo Informe sobre la Situación de los Derechos Humanos en el Perú. Doc. OEA/Ser.L/V/II.106, Doc. 59 rev., 2 de junio de 2000.

CONECTAS. Nota pública sobre regulamentação da Consulta Prévia. 2013. Disponível em http://www.conectas.org/pt/acoes/empresas-e-direitos-humanos/noticia/3387-nota-publicasobre-regulamentacao-da-consulta-prévia\#_ftn2. Acesso em: 30 Jan. 2014. 
DUE PROCESS OF LAW FOUNDATION. Derecho a la consulta y al consentimiento previo, libre e informado en América Latina - Avances y desafíos para su implementación en Bolivia, Brasil, Chile, Colombia, Guatemala y Peru. Washington, Fundacion par el debido proceso, 2015. Disponível em : http://www.corteidh.or.cr/tablas/libro1-2.pdf. Acesso em: 15 Jan. 2016.

GARCIA GIRALDEZ, Teresa. De la ciudadanía social a la ciudadanía multicultural. Cuadernos de trabajo social, 2000, $13: 33-51$.

HUMAN RIGHTS COUNCIL. Informe del Relator Especial sobre la situación de los derechos humanos y las libertades fundamentales de los indígenas. A/HRC/12/34/Add.2. Disponível em :http://observatoriopoliticasocial.org/sitioAnterior/index.php?

option=com zoo\&task=category\&category $\mathrm{id}=12 \&$ Itemid=450. Acesso em: 30 Oct. 2014.

LIMA, Antônio Carlos de Souza. Sobre tutela e participação : povos indígenas e formas de governo no Brasil, Séculos XX/XXI. Mana, vol.21, no.2 , Rio de Janeiro, 2015. Disponível em :http://dx.doi.org/10.1590/0104-93132015v21n2p425 . Acesso em: 16 Jan. 2015.

MARTINEZ COBO, J. R. Etude de la discrimination à l'encontre des populations autochtones, 1986. E/CN.4/Sub. 2/1986/7 et Add. 1 à 4.

XXXXXXX. L'effectivité du droit à la terre des peuples autochtones: le cas des Potiguara du Brésil, Dissertação de Mestrado, Université Catholique de Lyon, 2013.

OIT. Informe de la Comisión de Expertos en Aplicación de Convenios y Recomendaciones. Conferencia Internacional del Trabajo, 100.a reunión, Ginebra, 2011. Disponível em: http://www.ilo.org/wcmsp5/groups/public/---ed_norm/--

relconf/documents/meetingdocument/wcms_151559.pdf. Acesso em: 30 Oct. 2015.

OLIVEIRA, João Pacheco de; COHN, Clarice (orgs.). Belo Monte e a questão indígena. Brasília : ABA, 2014.

ONU. La situation des peuples autochtones dans le monde. Genève: Département de l'information des Nations Unies, 2010.

ONU. Report on the eleventh session, 2012 . Disponível em: http://www.un.org/esa/socdev/unpfii/documents/Indigenous_women_UNPFII_session_11.pdf. Acesso em: 16 nov. 2014.

RINALDI, K. Le droit des populations autochtones et tribales à la propriété dans le système interaméricain de protection des droits de l'homme. Le particularisme interaméricain. Paris : Editions A. Pedone, 2009. 
SANTA CRUZ, H. La discrimination raciale, étude spéciale sur la discrimination raciale dans les domaines politique, social et culturel. New York : Nations Unies, 1971.

SILVA, J. A. Poder Constituinte e Poder Popular. São Paulo: Malheiros, 2007.

TORBISCO, Neus. Simposio: Pluralismo jurídico y derechos humanos. Anuario de derechos humanos, No. 9, 2013.

TORRES, Aline. Os Kaingang, povo do curumim assassinado, em eterna fuga. El pais, 2016. Disponivel em : http://brasil.elpais.com/brasil/2016/01/12/politica/1452627574_159229.html. Acesso em: 16 jan. 2016.

VALIENTE, Aresio. Simposio: Pluralismo jurídico y derechos humanos. Anuario de derechos humanos, No. 9, 2013.

VERDUM, Ricardo. El indigenismo brasileño en tiempos de multiculturalismo. Alteridades. México, ene./jun. 2008.

VERDUM, Ricardo. Consulta Prévia, Direito dos Povos Indígenas, 2011. Disponível em : https://outrapolitica.wordpress.com/2011/10/24/consulta-prévia-direito-dos-povos-indígenas/

YACOUB, J. La question des peuples autochtones: retour aux fondements culturels et identitaires. Revue Etudes Interculturelles. Université Catholique de Lyon, 2009. 